\title{
Fe Coefficient - Development and Application of a Key Figure for Assessing the Efficiency of Alternative Drive Concepts in Trucks
}

\author{
Klaus-Peter Franke \\ Institute of Industrial Engineering and Supply Chain Management, Ulm University of Applied Sciences, Ulm, Germany
}

\author{
Email address: \\ franke@hs-ulm.de
}

\section{To cite this article:}

Klaus-Peter Franke. Fe Coefficient - Development and Application of a Key Figure for Assessing the Efficiency of Alternative Drive Concepts in Trucks. American Journal of Traffic and Transportation Engineering. Vol. 4, No. 2, 2019, pp. 48-55.

doi: $10.11648 /$ j.ajtte.20190402.12

Received: March 26, 2019; Accepted: April 28, 2019; Published: May 23, 2019

\begin{abstract}
Alternative drive concepts for trucks represent a highly promising way of reducing environmental pollution from road freight traffic. There are numerous proposals and pilot schemes pointing to the replacement of fossil fuel diesel by more sustainable energy sources. Along with drive chain electrification, it is a matter here of deploying alternative natural (gas) and synthetically generated fuels (eFuels) in combustion engines that might have to be modified. Given that a multitude of parameters on final energies, vehicle and travel route/ ambient conditions enter into the consumption calculation, it is usually difficult to compare the various drive concepts based on individually gauged consumptions/emissions. It is therefore proposed assessing the comparison on the basis of the same vehicle platform under practically the same deployment and route parameters. In other words, in order to examine an alternative energy as to its efficiency, only the vehicle drive chain is replaced - everything else remains as it is! The Fe coefficient in the heading is formulated to afford a simplified comparison of the various drive concepts under the above general conditions. Going into the Fe coefficient in each instance is solely the mean drive efficiency over the route $\eta_{\mathrm{E}-\mathrm{N}}$ and the payload to total load ratio under full capacity utilisation $\eta_{\mathrm{kon}}$ (design efficiency). The calculated Fe coefficient provides information on consumption. The greater the Fe the higher the consumption. Under the same vehicle platform - and with consideration given to the above general conditions - the Fe coefficients of the various drive variants can be related one to the other and, in this way, the increase or decrease in consumption as against, for instance, the diesel benchmark can be established. In conclusion, the Fe coefficient is used in three case studies to assess the effectiveness as against the diesel benchmark of two electric battery (Fuso eCanter, Tesla Semi) trucks and one LNG-driven Iveco Stralis NP 400 truck.
\end{abstract}

Keywords: Transport Logistics, Road Freight Traffic, Transport Efficiency, Energy Demand Calculation, Fe Coefficient

\section{Introduction}

Traffic contributes significantly to the worldwide consumption of fossil energies and associated environmental pollution. For instance whilst in Germany the non-traffic sectors contributed to the German climate protection plan being met between 1990 and 2014 by lowering the anthropogenic $\mathrm{CO}_{2} \mathrm{e}$-emissions from 1.248 billion tons to 0.902 billion tons, the 0.160 billion ton share of the traffic sector remained practically constant [1-2]. Irrespective of the fact that both private and goods traffic have exceeded local pollutant limits for years now and that diesel vehicles will be banned from city centres at some point in the future [3], the German government is requiring traffic-induced $\mathrm{CO}_{2} \mathrm{e}-$ emissions to be reduced to under 0.098 billion tons by 2030 [1]. Thus a lot needs to be done to bring about environmentally compatible traffic conditions in the remaining 11 years. As such, both the vehicle industry and the road haulage/logistics sector are currently busy working on a number of points for the improvement of transport and fuel efficiency. The up-and-coming innovations basically follow the three mega trends of automation, digitalisation and alternative drives [4].

In most instances, attempting to compare alternative drives 
(Chapter 2) as to their efficiency is an intricate business. In this respect, the idea in Chapters 3 and 4 is to devise an efficiency coefficient ( $\mathrm{Fe}$ coefficient) permitting an easy assessment to be made of the efficiency of alternative drive chains in the given truck under the same vehicle and route parameters. The following case studies focus on electric battery trucks and those with LNG engines. The purpose of the Fe coefficient is to assess the efficiency of the 7.5 ton Fuso eCanter (Chapter 5), the Tesla Semi (Chapter 6) and the 40 ton Iveco Stralis NP 400 (Chapter 7) over their diesel counterparts and, in this way, to contribute scientifically to the current pro \& contra discussion. The article closes with a summary, critical reflection and an outlook (Chapter 8).

\section{Alternative Drives in the Truck}

\subsection{Overview}

The alternative truck drives subject is focussed on changing the energy source away from mineral oil - as the scarce and environmentally damaging primary energy source - towards

1. Replacing diesel fuel in (correspondingly modified) combustion engines with less ecologically damaging alternative fuels like CNG (compressed natural gas with a $90 \%+$ methane share), LNG (liquefied methane), oxygen and $\mathrm{CO}_{2}$-neutral synthetic fuels or

2. Replacing combustion engines with electric motors with electrical energy generated when the truck is moving from hydrogen (fuel cells), supplied by way of current collectors from overhead lines or carried along in batteries.

Differences in the provision and/or storage of the energy source (overhead line, fuel cells, batteries, tanks for liquids, pressure tanks for gases, cooling), type of engine (combustion engine, el. motor) and drive unit (mechanical, hydrostatic, electric) plus differences in the energy densities of the energy supply possibly carried along result in differences in the net weight and/or permitted payload as well as different efficiencies in transforming final energy into motion energy. Having to consider all these factors can make a comparison of the vehicle efficiencies a highly intricate one.

\subsection{Electric Battery Drives}

Whilst cars with electric drives - either as hybrids or fully electric cars - have been coming from the belt for some years now, e-trucks are either still at the prototype stage or have just left it. Only as expensive conversions have e-trucks been in evidence up to shortly ago. That has involved removing the combustion engine-driven drive chain and replacing it with an electric drive chain. But things have also been happening here. Mitsubishi Fuso has seen its electric battery eCanter (7.5 tonner) coming off the belt in a pilot batch (550 all told) [5]. And its competitors (Daimler, MAN etc.) are also about to catch up. Given that up to the fall of 2017 only electrifying distributor trucks of a moderate range and a high stop-and-go share seemed feasible, the surprise was considerable on learning in November 2017 that Tesla planned to bring an electric battery long-distance truck (Tesla Semi) of a total $36.29 \mathrm{t}$ weight and an $800 \mathrm{~km}$ range onto the market in 2019 [6].

There is considerable speculation on the merits and drawbacks of electric battery trucks as replacements for diesel vehicles. On the one hand, it involves how electrical energy, if at all, can be provided nationwide and more or less quickly "tapped", on the other, of how practical and efficient electric utility vehicles really are compared to diesel trucks or those run on alternative energies. The last question will be gone into with the example of the Fuso eCanter and the Tesla Semi.

\subsection{Gas Engines for the Combustion of $L N G$ and $C N G$}

Iveco, Scania (Otto principle) [7] and Volvo (HPDI principle) are equipping heavy trucks with gas engines [8]. The prime functional difference of interest here between engines operating on the basis of the Otto principle and those on the basis of the HPDI principle (High-Pressure Direct Injection) is their efficiency $\eta_{e, o p t}$. $[18$, S. 20] indicates that fuel efficiency in engines functioning on the basis of the Otto principle is down by 15 to $25 \%$ as against diesel whilst in [9, Page XVI] the talk is of where optimized natural gas engines functioning on the basis of the Otto principle they should ideally be able to attain up to $95 \%$ of diesel efficiency. Should Iveco's announcement of its new Stralis NP 460 having "up to $15 \%$ lower fuel consumption" also relate to comparable gas engines, then the new Cursor 13 NP engine has an efficiency surpassing $90 \%$ of a comparable diesel unit. In contrast, HPDI engines (self-igniter i.e. „liquid spark plug") have a fuel consumption which energetically is at the same level as for conventional diesel engines [9, S. 63]. Basically, both process principles allow the use of LNG and $\mathrm{CNG}$ although the engines have to be adjusted to the way in which the natural gas is provided.

Accepting the fact of the different ranges, the design efficiency $\eta_{k o n}$ (for ratio of max. permitted payload to max. permitted total weight see Formula 9) differences between trucks with $\mathrm{CNG}$ and those with LNG appear negligible. Essentially, natural gas engine technology has only a marginal impact on comparing on-board vehicle $\mathrm{CNG}$ and LNG [9, Page XII]. According to an LNG v. CNG storage mass comparison (gross: tare weight plus natural gas mass) in [9, Page 34], LNG (gas pressure 15 - 20 bar, cooled to $161.52{ }^{\circ} \mathrm{C}$ ) - given twice the range - takes up roughly the same space in gross terms as $\mathrm{CNG}$ (gas pressure 200 bar) but with CNG weighing only half as much in gross terms. This points to roughly the same gross weight of CNG and LNG storage given comparable energy content and ranges. With the available construction space seeming to be the limiting factor, a truck run on LNG has approximately twice the range of one running on CNG. For a typical articulated lorry based on the OC13 gas engine ( $302 \mathrm{~kW}$ ) over a level stretch, Scania indicates an approx. 1,100 km range and a $500 \mathrm{~km}$ range for LNG and CNG technologies, respectively [7]. Contrasting with this, Iveco indicates ranges of 570 to $600 \mathrm{~km}$ and 1,600 
km with CNG and LNG respectively for its fully loaded Stralis NP460 [19, S. 15].

\section{The Energy Demand Calculation Theory}

\subsection{Modelling}

The (final) energy consumption $E_{E}$ of a truck (Formula 1) is conditional upon the work (corresponds to the effective energy to be provided $E_{N}$ ) which the vehicle has to perform along a distance $s$ between source and sink for overcoming the external motion resistances $F_{\text {ges }}=F_{\text {mass }}+F_{\text {aer }}$ with consideration given to an efficiency $\eta_{E-N}$ (cf. [10]).

$$
E_{E}=\int \frac{1}{\eta_{E-N}} \cdot\left[F_{\text {mass }}+F_{\text {aer }}\right] \cdot d s
$$

The across-the-route $s$ variable efficiency $\eta_{E-N}$ of the power transmission between the input of final energy from the tank and the provision of effective energy to the drive wheels considers the efficiencies $\eta_{E-m o t}$ between energy reservoir and engine, $\eta_{m o t}=\eta_{e}$ of the engine as well as $\eta_{m o t-N}$ between engine and drive wheels (Formula 2)

$$
\eta_{E-N}=\eta_{E-m o t} \cdot \eta_{m o t} \cdot \eta_{m o t-N}
$$

By dispensing with the integer spelling and by entering mean values over distance $s$ Formula 1 can be transferred into Formula 3. The increase of the energy consumption $E_{E}$ due to a divergence of efficiency $\eta_{E-N}$, i.e. principally that of the share $\eta_{m o t}$ of the efficiency $\eta_{E-N \text {,opt }}$ at the ideal operating point, is taken into account by a (drive line) factor $\alpha_{1}$. It can also consider consumption increases due to non-ideal operations e.g. constant crawling speed under internal company transport operations.

$$
E_{E}=\frac{\propto_{1}}{\eta_{E-N, o p t}} \cdot\left[\bar{F}_{\text {mass }}+\bar{F}_{a e r}\right] \cdot s
$$

The mass-dependent mean motion resistance $\bar{F}_{\text {mass }}$ is calculated (Formula 4) by a (route) factor $\alpha_{2}$, the rolling friction coefficient $\mu_{R}$, gravitational acceleration $g$ and the masses from vehicle net weight $m_{E G}$ and payload $m_{N L}$.

$$
\bar{F}_{\text {mass }}=\alpha_{2} \cdot \mu_{R} \cdot\left(m_{E G}+m_{N L}\right) \cdot g
$$

Factor $\alpha_{2}$ takes into account (Formula 5) the share transformed into heat from braking along the distance $s$ after accelerating and/or surmounting inclines by applying a mean fictitious acceleration $\bar{a}$ and/or mean fictitious incline $\bar{I}$. The effect of not converting any energy into heat from braking e.g. when travelling at a constant speed on the level, as a consequence, produces $\alpha_{2}=1 . \alpha_{2}$ is reduced when kinetic/potential energy placed beforehand into the system is recuperable under braking conditions.

$$
\alpha_{2}=\frac{1}{\mu_{R}} \cdot\left(\frac{\bar{a}}{g}+\mu_{R}+\bar{I}\right)
$$

The mean air resistance $\bar{F}_{\text {aer }}$ arises (Formula 6) from the air density $\rho_{L}=1.2 \mathrm{~kg} / \mathrm{m}^{3}$, the product of cross-section area $A$ and air resistance coefficient $c_{W}$ of the truck and the mean vehicle speed $\bar{v}$. The impact of wind is negligible!

$$
\bar{F}_{a e r}=0,5 \cdot \rho_{L} \cdot A \cdot c_{W} \cdot \bar{v}^{2}
$$

\subsection{Discussion of Vehicle Parameter $\alpha_{1}$ and Road Parameter $\alpha_{2}$}

The effect of using Formula 4 for the mass-dependent mean motion resistance $\bar{F}_{\text {mass }}$ in Formula 3 and cancelling it as per $\alpha_{1}$ produces the connection between $\alpha_{1}$ and $\alpha_{2}$ under given energy consumption $E_{E}$ (Formula 7).

$$
\propto_{1}=\frac{E_{E}}{s} \cdot \frac{\eta_{E-N, o p t}}{\left[\propto_{2} \cdot \mu_{R} \cdot\left(m_{E G}+m_{N L}\right) \cdot g+\bar{F}_{a e r}\right]}
$$

By plotting $\alpha_{1}$ via $\alpha_{2}$, the possible value pairs $\left(\alpha_{1}, \alpha_{2}\right)$ for a given energy consumption $E_{E}$ would create a sub-linear hyperbola course in the top right quadrant of an axis cross with origin $(1,1)$. The maximum of $\alpha_{1}$ arises for $\alpha_{2}=1$ and vice versa. The higher the consumption, the further away the hyperbola is from the origin and/or the larger become the maxima of $\alpha_{1}$ and $\alpha_{2}$.

In [11] the consumption of six fully loaded articulated lorries (40 t, Euro-6 standard), which the VerkehrsRundschau tested on a five route-sectioned course of varying difficulties from 2014 to 2016, was analysed with Formula 3. The mean values for $\alpha_{1, \max }$ (for $\alpha_{2}=1$ ) of the six trucks lay between 1.17 (easy-to-negotiate autobahn) and 1.75 (road) whilst the mean values for $\alpha_{2, \max }$ (for $\alpha_{1}=1$ ) of the six trucks lay between 1.39 (easy-to-negotiate autobahn) and $>1.89$ (road).

\subsection{Formulation of a Vehicle Efficiency Coefficient Fe}

Vehicle efficiency is to be assessed for full capacity utilisation on the basis of the specific (final) energy consumption $e_{E}$ in $\mathrm{kWh}$ per transported ton of payload and $\mathrm{km}$. Following change-over and introduction of a design efficiency $\eta_{\text {kon }}$, Formula 3 can be transferred into Formula 8.

$$
\frac{E_{E}}{m_{N L, z u l} \cdot s}=\frac{\alpha_{1}}{\eta_{E-N, o p t} \cdot \eta_{\text {kon }}} \cdot \frac{\left[\bar{F}_{\text {mass }}+\bar{F}_{a e r}\right]}{m_{\text {ges }, \text { zul }}}=e_{E}
$$

The design efficiency $\eta_{k o n}$ stipulates the ratio of maximum permitted payload $m_{N L, z u l}$ to max. permitted total weight $m_{g e s, z u l}=m_{E G}+m_{N L, z u l}$ (Formula 9). The larger the $\eta_{k o n}$, the smaller is the dead weight $m_{E G}$ to be moved. For instance, tanks / batteries with energy sources of a comparable low energy density result in a significant increase in vehicle weight $m_{E G}$ when substantial vehicle ranges are to come about. Furthermore, the net weight of pressure tanks, e.g. for storing liquid hydrogen, should not be underestimated.

$$
\eta_{k o n}=\frac{m_{N L, z u l}}{m_{g e s, z u l}}
$$

Finally, the proposal is to introduce a vehicle efficiency coefficient $\mathrm{Fe}$ to allow Formula 8 to pass over into Formula 10. 


$$
e_{E}=F e \cdot \frac{\left[\bar{F}_{m a s s}+\bar{F}_{a e r}\right]}{m_{\text {ges }, \text { zul }}}
$$

To be entered into the vehicle efficiency coefficient $F e$ is the power provision efficiency under optimum operating conditions $\eta_{E-N, o p t}$, factor $\alpha_{1}$ and design efficiency $\eta_{k o n}$ (Formula 11).

$$
F e=\frac{\alpha_{1}}{\eta_{E-N, o p t} \cdot \eta_{k o n}}
$$

The vehicle efficiency coefficient $\mathrm{Fe}$ enables drive variants to be tested (for the first time) under the same vehicle (especially aerodynamics, tyres, permitted total weight) and route parameters (especially height profile, speed profile, weather conditions) The smaller the $F e$, the lower the specific energy consumption $e_{E}$ or the higher is the vehicle efficiency per tkm under given vehicle and route parameters.

\section{Case Study 1 - Fuso eCanter}

The Fuso eCanter is the first line-produced electric battery 7.5 tonner. It is fitted to the chassis of the corresponding diesel version (FE 160) of the Fuso Canter, which is assembled in Portugal [5, 12].

On the basis of the vehicle efficiency coefficient $\mathrm{Fe}$ developed in Chapter 3, the intention is to compare the efficiency of the electric drive chain of the eCanter with that of the diesel-driven FE 160 Canter. This takes no account of the smaller range of the eCanter and the scope it offers for braking energy recuperation.

Given that nothing further is known of the deployment conditions - and for the sake of simplicity - the assumption at the outset is that in operating the two vehicles no difference exists in the mean deviation from the ideal operating point $\alpha_{1}$. Thus, $\alpha_{l}$ can be set to 1 in both cases.

The chassis load-bearing capacity of the eCanter is thought to be $9,000 \mathrm{lbs}$ or $4,080 \mathrm{~kg}$ which is approximately $10 \%$ under that of the Fuso FE 160 Canter $(4,500 \mathrm{~kg})$ [5]. The inclusion of an additional $1,165 \mathrm{~kg}$ for lightweight van body and tail-lift reduces the net load-bearing capacity $\left(m_{N L, \max }\right)$ to $2,915 \mathrm{~kg}$ (eCanter) and to $3,335 \mathrm{~kg}$ (FE 160) and design efficiencies $\eta_{k o n}$ arise of 0.39 (eCanter) and 0.45 (FE 160). (Note: increasing the eCanter range would raise the weight of the battery and, as a result, negatively affect its design efficiency $\eta_{\text {kon }}$.)

The effect of continuing to set the efficiency $\eta_{E-N, \text { opt }}$ of the electric battery drive chain to 0.91 and that of the mechanical-diesel to 0.38 results in $\mathrm{Fe}$ coefficients of 2.82 (eCanter) and 5.94 (FE 160) respectively. Setting the two $\mathrm{Fe}$ figures relative to each other gives rise to a situation where in respect of both cases $\alpha_{1}=1$ - consumption of the Fuso eCanter per transported ton and $\mathrm{km}$ is at least (without any energy recuperation from braking) $53 \%$ under that of the diesel-driven FE 160. cf. Table 1.

Table 1. Vehicle efficiency comparison Fuso eCanter v. Fuso FE 160 (Diesel).

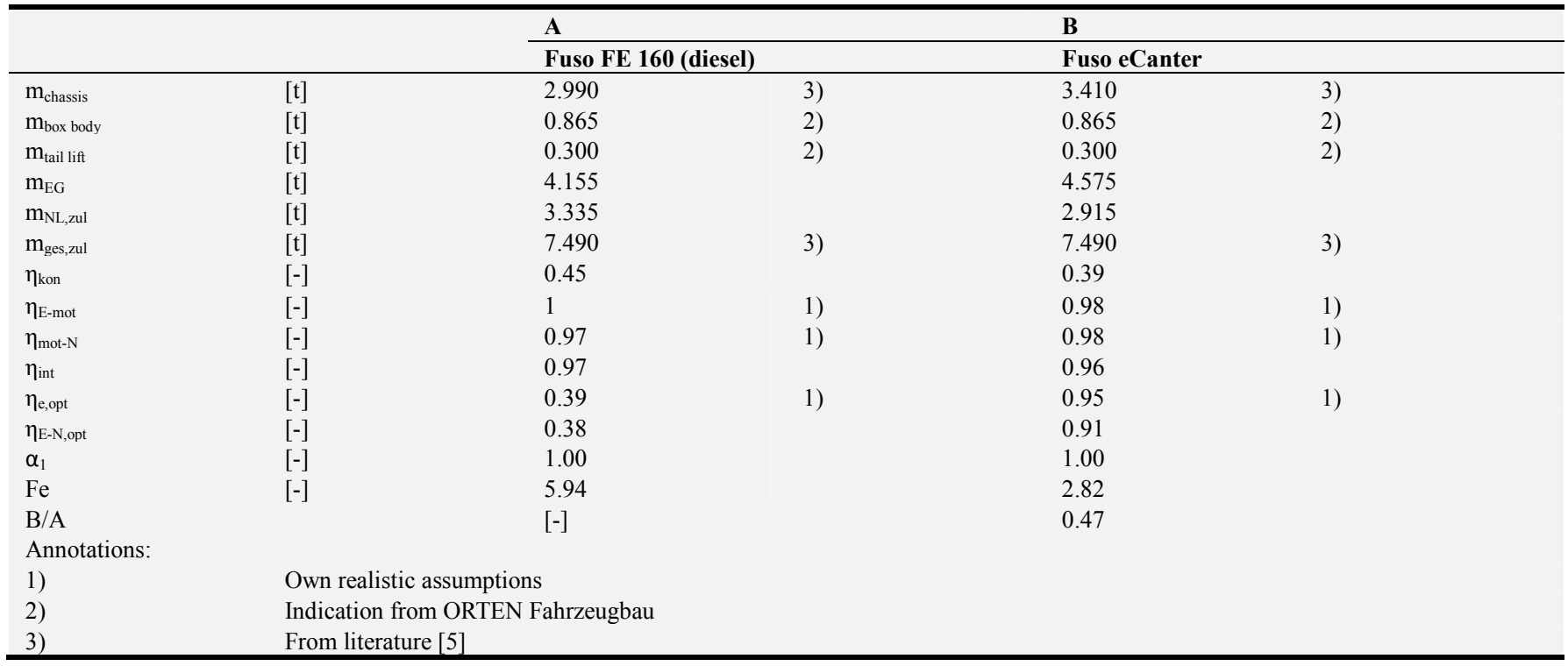

\begin{tabular}{|c|c|c|c|c|c|}
\hline \multirow[b]{3}{*}{$\mathrm{m}_{\mathrm{EG}}$} & \multirow[b]{3}{*}[\mathrm{t}]{} & \multirow{2}{*}{\multicolumn{2}{|c|}{$\begin{array}{l}\text { A } \\
\text { Fiktitious articulated lorry (diesel) }\end{array}$}} & \multirow{2}{*}{\multicolumn{2}{|c|}{$\begin{array}{l}\text { B } \\
\text { Tesla eSemi }\end{array}$}} \\
\hline & & & & & \\
\hline & & 15.00 & 1) & 27.14 & \\
\hline $\mathrm{m}_{\mathrm{NL}, \mathrm{zul}}$ & {$[\mathrm{t}]$} & 21.29 & & 9.15 & \\
\hline $\mathrm{m}_{\mathrm{ges}, \mathrm{zul}}$ & {$[\mathrm{t}]$} & 36.29 & $\leftarrow$ & 36.29 & 2) \\
\hline$\eta_{\text {kon }}$ & {$[-]$} & 0.59 & & 0.25 & \\
\hline$\eta_{\text {E-mot }}$ & {$[-]$} & 1 & 1) & 0.98 & 1) \\
\hline$\eta_{\text {mot-N }}$ & {$[-]$} & 0.98 & 1) & 0.98 & 3) \\
\hline$\eta_{\mathrm{e}, \mathrm{opt}}$ & {$[-]$} & 0.40 & 1) & 0.95 & 1) \\
\hline
\end{tabular}

Table 2. Establishing payload break-even Tesla eSemi v. fictitious articulated lorry (Diesel). 


\begin{tabular}{llll}
\hline & \multicolumn{1}{c}{ A } & B \\
\cline { 3 - 4 } & & Fiktitious articulated lorry (diesel) & Tesla eSemi \\
\hline$\eta_{\mathrm{E}-\mathrm{N}, \mathrm{opt}}$ & {$[-]$} & 0.39 & 0.91 \\
$\alpha_{1}$ & 1.00 & 1.00 \\
$\mathrm{Fe}$ & {$[-]$} & 4.35 & 4.35 \\
$\mathrm{~B} / \mathrm{A}$ & {$[-]$} & 1.00 & \\
Annotations: & {$[-]$} & & \\
$1)$ & & \\
$2)$ & Own realistic assumptions & \\
$3)$ & From literature [6] & & \\
\hline
\end{tabular}

\section{Case Study 2 - Tesla Semi}

The Tesla Semi - referred to below as eSemi - is an electric battery truck traction unit which with its total weight $m_{\text {ges }}$ of $36.29 \mathrm{t}$ together with trailer is reported to have a range of up to 500 miles or $800 \mathrm{kms}$ [6]. Speculations are rife bearing in mind that battery details are as yet unknown. To move the eSemi $\left(\mu_{R}=0.0048, c_{W}=0.36\right)$ with its 36.29 tons on a level stretch at a constant speed of $v=65$ m.p.h, own calculations would point to an electrical power output of $110 \mathrm{~kW}$. A 500 mile range would require an approx. $840 \mathrm{kWh}$ battery capacity. Basing this on a lithium-ion battery of a $200 \mathrm{Wh} / \mathrm{kg}$ energy density would entail an approx. 4.2 ton battery weight (cf.[6]: „Analysts have estimated the weight of the battery pack at perhaps 10,000 pounds" $(=4.55$ tons $))$. Given that the net weight of the Tesla eSemi is unknown, the $\mathrm{Fe}$ coefficients (Formula 12) of two articulated trucks are to be compared to establish break-even for the loading weight $m_{N L}$ upwards from which the specific energy consumption $\mathrm{e}_{\mathrm{E}}$ (in $\mathrm{kWh}$ per transported ton of payload and $\mathrm{km}$, see above) of the articulated lorry based on the Tesla eSemi is greater than that of a fictitious diesel-driven counterpart with a net weight $m_{E G}$ of a customary 15 tons.

$$
F e_{T S, e l}=F e_{T S, \text { diesel }}
$$

By incorporating Formulas 11 and 9, Formula 12 can be unravelled according to $\mathrm{m}_{\mathrm{NL}, \mathrm{TS}, \mathrm{el}}=\mathrm{m}_{\mathrm{NL}, \text { BreakEven }}$ (Formula 13).

$$
m_{N L, \text { BreakEven }}=\frac{1}{F e_{T S, \text { diesel }}} \cdot\left(\frac{\alpha_{1} \cdot m_{g e s, z u l}}{\eta_{E-N, \text { opt }}}\right)_{T S, e l}
$$

Formula 11 - and with the technical data of the dieseldriven counterpart in Table 2 taken into account - allows $F e_{T S \text {,diesel }}$ to be calculated to 4.35 . As such, Formula 13 and the technical data of the eSemi in Table 2 can continue to be used to calculate an $\mathrm{m}_{\mathrm{NL} \text {,BreakEven }}$ of 9.15 tons (again in each instance $\alpha_{1}=1$ ). This means that only when the payload proportion to the total weight is under $25 \%$ does the eSemi use more energy per transported payload and $\mathrm{km}$ than its diesel-driven counterpart This means that the extra weight of the-eSemi traction unit resulting from the 4.2 ton battery weight (see above) is not of importance for consumption as long as the reduced permitted payload of the e-Semi has no limiting effect. Given an average weight per pallet of what is usually under $200 \mathrm{~kg}$ and double-storey loading, a maximum required payload of $\mathrm{m}_{\mathrm{NL} \text {, max }}=66.0 .2 \mathrm{t}=13.2 \mathrm{t}<<25 \mathrm{t}=$ $\mathrm{m}_{\mathrm{NL}, z u l}$ of a conventional $40 \mathrm{t}$ articulated lorry can be reckoned with for groupage freight carriers!

\section{Case Study 3 - Iveco Stralis NP 400}

The Iveco Stralis NP $400(294 \mathrm{~kW})$ is an LNG-driven truck traction unit with gas engine operating on the Otto principle. Two LNG tanks with a total 1,080 litre capacity should "easily" ensure a $1,500 \mathrm{~km}$ range. The Stralis NP 400 with a $7,580 \mathrm{~kg}$ net weight only weighs $200 \mathrm{~kg}$ more than the Stralis XP 410 - its diesel-driven counterpart $[13,14]$. Multiplying the 1,080 litre volumetric capacity by the $0.423 \mathrm{~kg} /$ litre density of LNG at the evaporation point $\left(-161,52^{\circ} \mathrm{C}\right)[15]$ results in a tank capacity of just under $460 \mathrm{~kg} \mathrm{LNG}$ or with a lower calorific value of 13.98 $\mathrm{kWh} / \mathrm{kg}$ [16] an energy content of $6,430 \mathrm{kWh}$ or with 9.97 $\mathrm{kWh} /$ litre $_{\mathrm{DA}}[16]$ an equivalent of 645 litres of diesel. Resulting from a 1,500 km range under full load (see above) is a very conservatively set mean consumption of $645 / 15=43$ litres $\mathrm{DÄ} / 100 \mathrm{~km}$. As a comparison, in [9, S.65 and S. 68] an energy demand of $383 \mathrm{kWh} / 100 \mathrm{~km}$ or 38.4 litre $\mathrm{DÄ}$ is indicated for a 40 tonner with gas engine as against a 31 litre consumption of its diesel-driven counterpart. This means that the gas engine efficiency continues to attain only $31 / 38.4=80 \%$ of the efficiency of the diesel engine, whilst in [9], see above, the talk ideally is of up to a $95 \%$ efficiency of the diesel engine.

Table 3. Vehicle efficiency comparison 40 tonner Stralis NP 400 with $\eta_{e, o p t}=0.38$ v. Stralis XP 420 (Dies.).

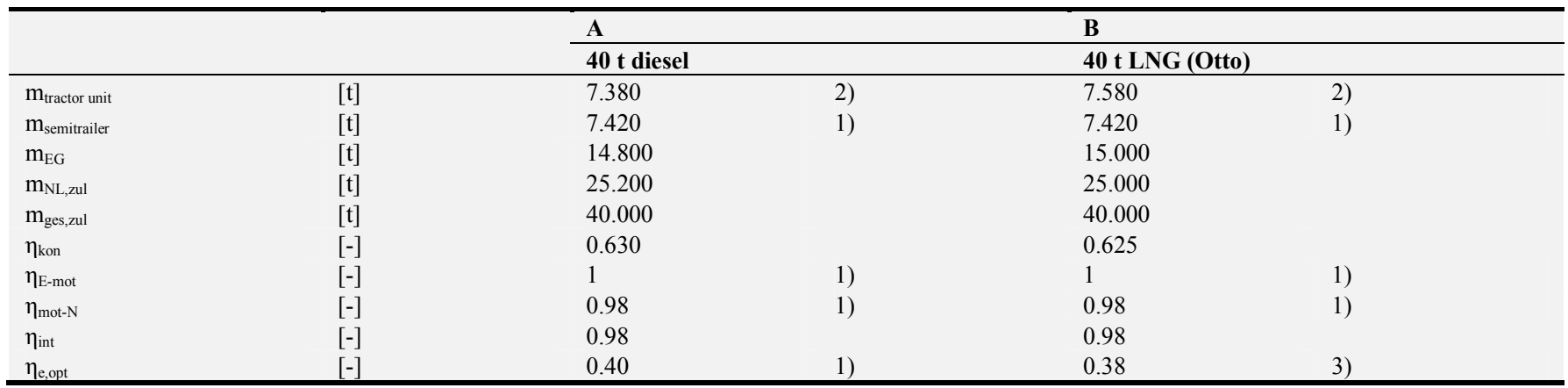




\begin{tabular}{llll}
\hline & & A & B \\
\cline { 3 - 4 } & & $\mathbf{4 0 ~ t \text { diesel }}$ \\
\hline$\eta_{\mathrm{E}-\mathrm{N}, \mathrm{opt}}$ & {$[-]$} & 0.39 & $\mathbf{4 0 ~ t ~ L N G ~ ( O t t o )}$ \\
$\alpha_{1}$ & 1.00 & 0.37 \\
$\mathrm{Fe}$ & {$[-]$} & 4.05 & 1.00 \\
$\mathrm{~B} / \mathrm{A}$ & 1.06 & 4.30 \\
Annotations: & {$[-]$} & & \\
$1)$ & & \\
$2)$ & Own realistic assumptions & \\
$3)$ & From literature [13] & \\
\hline
\end{tabular}

Table 4. Vehicle efficiency comparison 40 tonner Stralis NP 400 with $\eta_{e, o p t}=0.32$ v. Stralis XP 420 (Dies.).

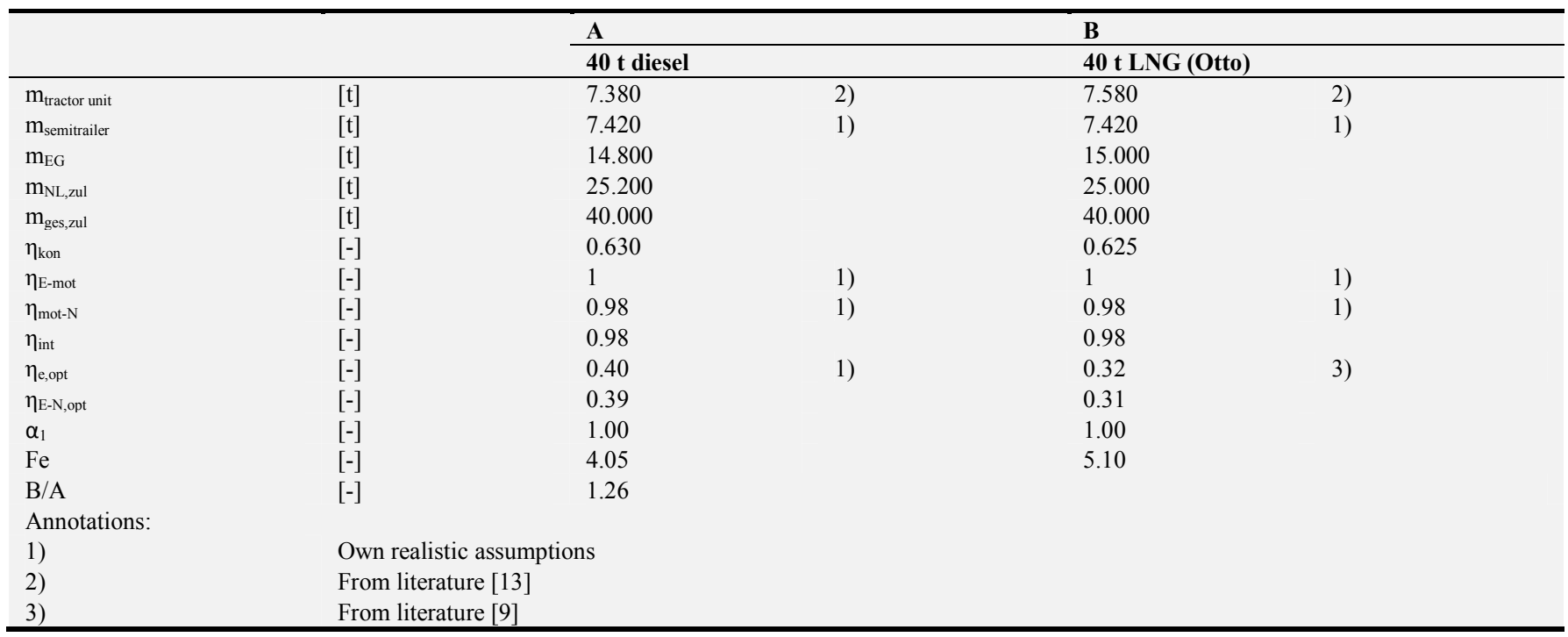

The result of recording the efficiency $\eta_{e, o p t}$ of the LNG engine once with $0.38=0.95 \cdot 0.40$ and once with $0.32=$ $0.80 \cdot 0.40$ are $\mathrm{Fe}$ coefficients of the LNG traction unit of 4.3 and 5.1 respectively as against a $4.05 \mathrm{Fe}$ coefficient for the diesel-driven counterpart $\left(\eta_{e, o p t}=0.40\right)$. Setting the $F e$ coefficients relative to one another results in that - for all instances of $\alpha_{1}=1$ - the consumption of the gas-driven articulated lorry per transported ton and $\mathrm{km}$ is approx. $6 \%$ or $26 \%$ higher than that of the diesel-driven articulated lorry. Cf. Tables 3 and 4! (Note: even when this comparison of the specific final energy demand $\mathrm{e}_{\mathrm{E}}$ in $\mathrm{kWh}$ (tank-to-wheel) is unfavourable towards the fossil natural gas driven truck $(\mathrm{NG})$, it still does not say anything about its environmental friendliness - in particular on its admixture with biogas. Compare in this respect [9, S. 2-69-2-70]).

\section{Conclusion, Critical Reflection, Outlook}

As essentially a multitude of parameters (Formula 8) have to be inputted into the energy demand calculation (Chapter 3), comparing different drive chain trucks on their consumption (and environmental compatibility) can be highly complex. The answer is easy when replying to the question which generally satisfies for an initial assessment „To what extent does the fuel consumption per transported ton and $\mathrm{km}$ (under full load capacity) change when the drive chain is replaced in a given truck but with the outer shape and permitted total weight (vehicle parameters) and the deployment conditions (route parameters) remaining the same ?" In this instance, it suffices to ascertain the vehicle efficiency coefficients $\mathrm{Fe}$ as developed in this article (Chapter 3) for the various drive concepts (Formula 11) and compare them. The lower the $\mathrm{Fe}$, the lower the specific final energy consumption $e_{E}$ and the higher is the vehicle efficiency in comparison.

But any simplification has its drawbacks. This kind of (initial) comparison takes no account of possibly different ranges of the vehicles which, under certain circumstances, necessitate adjustments to the net weight $m_{E G}$ and/or the permitted payload $m_{N L, z u l}$ or the possibility of recuperating energy when braking, which, in turn, results in a reduction of the specific consumption $e_{E}$.

The outcome of Case Study 1 (Chapter 4) concerned with an (initial) comparison of the efficiency of the Fuso eCanter over its diesel-driven counterpart in the shape of the pendant Fuso Fe 160 (both 7.5 tonners) was one of the eCanter requiring approx. 50\% less final energy per transported ton and mileage undertaken than the FE 160.

The outcome of Case Study 2 (Chapter 5) concerned with the efficiency of the Tesla Semi compared to a fictitious diesel-driven counterpart is one of the electric battery Tesla-Semi only needing additional final energy per transported and the mileage undertaken when the payload share to the total weight of $m_{g e s}=36.29 \mathrm{t}$ falls under $25 \%$, i.e. 9.15 t. 
The outcome of Case Study 3 (Chapter 6) concerned with the efficiency of a gas-driven $40 \mathrm{t}$ articulated lorry over its diesel-driven counterpart is one whereby - conditional upon the efficiency $0.8 \leq \eta_{e, o p t} \leq 0.95$ of the gas engine (Otto principle) - the final energy demand per tkm is $6 \%$ to $26 \%$ higher than for the diesel-driven counterpart.

For simplification purposes, $\alpha_{1}=1$ was assumed for all the three case studies. The risks inherent in the differences in ranges were knowingly accepted. No consideration was given to the recuperation possibilities of the electric battery vehicles.

This article focussed on a calculation proposal to compare specific final energy demands $e_{E}$ in $\mathrm{kWh}_{\mathrm{E}} / \mathrm{t} / \mathrm{km}$. It goes without saying it allows deductions to be made as to primary energy demands $e_{P}$ in $\mathrm{kWh} / \mathrm{t} / \mathrm{km}$ as well as $\mathrm{CO}_{2} \mathrm{e}-$ emissions $m_{\mathrm{CO} 2}$ in $\mathrm{kg} / \mathrm{t} / \mathrm{km}$.

\section{Abbreviations}

\begin{tabular}{|c|c|}
\hline A & cross-section area \\
\hline $\mathrm{DÄ}$ & diesel equivalent \\
\hline $\mathrm{E}_{\mathrm{E}}$ & final energy provided \\
\hline $\mathrm{E}_{\mathrm{N}}$ & useful energy supplied at the wheels \\
\hline$F_{\text {mass }}$ & mass-dependent motion resistance \\
\hline $\mathrm{F}_{\mathrm{aer}}$ & air resistance \\
\hline $\mathrm{Fe}$ & vehicle efficiency coefficient \\
\hline HPDI & High Pressure Direct Injection \\
\hline I & incline \\
\hline TS & Tesla Semi \\
\hline $\mathrm{c}_{\mathrm{W}}$ & air resistance coefficient \\
\hline$e_{e}$ & specific final energy consumption \\
\hline$e_{p}$ & specific primary energy consumption \\
\hline el & electric \\
\hline g & gravitational acceleration \\
\hline $\mathrm{m}_{\text {tractor unit }}$ & net mass of tractor unit \\
\hline $\mathrm{m}_{\text {semitrailer }}$ & net mass of semitrailer \\
\hline $\mathrm{m}_{\text {Chassis }}$ & net mass of chassis \\
\hline $\mathrm{m}_{\text {box body }}$ & net mass of box body \\
\hline $\mathrm{m}_{\text {tail lift }}$ & net mass of tail lift \\
\hline $\mathrm{m}_{\mathrm{EG}}$ & net mass \\
\hline $\mathrm{m}_{\mathrm{NL}}$ & payload \\
\hline $\mathrm{m}_{\mathrm{NL}, \mathrm{zul}}$ & permissible payload \\
\hline $\mathrm{m}_{\text {ges,zul }}$ & gross vehicle weight \\
\hline $\mathrm{m}_{\mathrm{CO} 2}$ & mass of $\mathrm{CO}_{2} \mathrm{e}$-emissions \\
\hline $\mathrm{S}$ & distance \\
\hline $\mathrm{v}$ & speed \\
\hline$\alpha_{1}$ & drive line factor \\
\hline$\alpha_{2}$ & route factor \\
\hline$\eta_{\mathrm{e}}=\eta_{\mathrm{mot}}$ & motor efficiency \\
\hline$\eta_{\mathrm{e}, \mathrm{opt}}$ & motor efficiency at the ideal operating point \\
\hline$\eta_{\text {E-mot }}$ & energy efficiency between final energy supply and motor terminal \\
\hline$\eta_{\mathrm{E}-\mathrm{N}}$ & energy efficiency between final energy supply and wheels \\
\hline$\eta_{\mathrm{E}-\mathrm{N}, \mathrm{opt}}$ & optimum energy efficiency between final energy supply and wheels \\
\hline$\eta_{\text {int }}$ & $=\eta_{\mathrm{E}-\mathrm{mot}}+\eta_{\mathrm{mot}-\mathrm{N}}$ \\
\hline$\eta_{\text {kon }}$ & design efficiency \\
\hline$\eta_{\text {mot }}=\eta_{\mathrm{e}}$ & motor efficiency \\
\hline$\eta_{\text {mot-N }}$ & energy efficiency degree between motor shaft and wheels \\
\hline$\mu_{\mathrm{R}}$ & rolling friction coefficient \\
\hline$\rho_{\mathrm{L}}$ & air density \\
\hline
\end{tabular}




\section{References}

[1] N. N.: Klimaschutzplan 2050. Deutsches Bundesministerium für Umwelt, Naturschutz und nukleare Sicherheit (BMU), Arbeitsgruppe IK III 1, Berlin. November 2016. https://www.bmu.de/fileadmin/Daten_BMU/Download_PDF/ Klimaschutz/klimaschutzplan_2050_bf.pdf.

[2] Weiß, Martin; Welke, Mareike: Klimaschutz in Zahlen. Fakten, Trends und Impulse deutscher Klimapolitik. Deutsches Bundesministerium für Umwelt, Naturschutz, Bau und Reaktorsicherheit (BMUB), Referat KI I 1, Berlin. April 2017.

http://www.bmub.bund.de/fileadmin/Daten_BMU/Pools/Brosc hueren/klimaschutz_in_zahlen_2017_bf.pdf.

[3] N. N.: Gerichts-Hammer: Städte dürfen Diesel-Fahrverbote erlassen. Onlineportal Merkur.de, München, 28.02.18. https://www.merkur.de/politik/hammer-urteilbundesverwaltungsgerichts-in-leipzig-staedte-duerfen-dieselfahrverbote-erlassen-zr-9649379.html.

[4] N. N.: Trend guide - Alles was 2018 wichtig ist! ETM-Verlag, Stuttgart, 2018.

[5] Crissey, Jeff: Mitsubishi Fuso delivers first all-electric eCanter trucks to customers. https://www.ccjdigital.com/mitsubishifuso-delivers-first-all-electric-ecanter-trucks-to-customers/. Commercial Carrier Journal. Posted on 14.09.2017.

[6] Gross, L. J.: Analysis: The Tesla semi's major selling points. https://www.joc.com/technology/analysis-telsa-semis-majorselling-points_20171228.html. joc.com. Posted on 28.12.2017.

[7] Hoffmann, J.: Scania zieht nach - Schwedischer LkwHersteller setzt zunehmend auf Erdgas. transaktuell 5. ETMVerlag, Stuttgart, 15.2.2018.

[8] Schmidt, B.: Iveco und Scania geben Gas. Onlineportal Frankfurter Allgemeine faz.net, Frankfurt, 03.12.2017. http://www.faz.net/aktuell/technik-motor/motor/lastwagenmit-lng-iveco-und-scania-geben-gas-15311802-p2.html.

[9] Bünger, U. et alt.: Vergleich von CNG und LNG zum Einsatz in Lkw im Fernverkehr. Abschlussbericht. Ludwig-BölkowSystemtechnik GmbH, Ottobrunn, Mai 2016. http://www.lbst.de/ressources/docs2016/1605_CNG_LNG_En dbericht_public.pdf.

[10] Franke, K.-P.: Raising the efficiency of Long Distance Road Haulage by Introducing Extra Long Trucks. Proceedings of the VII International Scientific Conference "Logistic Systems in Global Economics", S. 21 -29. Krasnoyarsk 2017. http://vseup.ru/static/files/2017.pdf.

[11] Haag, M.; Künzel, T.: Plausibilisierung eines Rechenmodells für Fernverkehrs-Lkw. Master-Projektarbeit an der Hochschule Ulm. 03.2018 (not published).

[12] N. N.: Fuso Ecanter. WIKIPEDIA. https://de.wikipedia.org/wiki/Fuso_Ecanter. (Download 8.3.2018).

[13] Burgdorf, J.: Supertest Iveco Stralis NP 400: Spass mit dem Gas? Trucker.de -Test \& Technik -Tests. Springer Fachmedien München $\mathrm{GmbH}$, München, 10.01.2018. $\mathrm{http}: / / w w w . t r u c k e r . d e /$ supertest-iveco-stralis-np-400-spassmit-dem-gas-2036790.html.

[14] N. N.: Sattelzugmaschine Scania LNG - Flüssiges ERDGAS für Langstreckenstars. Zukunft ERDGAS $\mathrm{GmbH}$, Berlin. https://www.erdgas.info/erdgas-mobil/erdgasfahrzeuge/scania/scania-pg-lng-340/. (Download 26.04.2019).

[15] Linde: LNG (Erdgas flüssig). Produktdatenblatt, Stand 21.04.2008. https://produkte.lindegase.de/db_neu/lng_erdgas_fluessig.pdf.

[16] Wurster, R. et alt.: LNG als Alternativkraftstoff für den Antrieb von Schiffen und schweren Nutzfahrzeugen, S. 95. Kurzstudie im Auftrag des Deutschen Bundesverkehrsministeriums für Verkehr und digitale Infrastruktur (BMVI). Deutsches Zentrum für Luft- und Raumfahrt e. V. (DLR), Institut für Verkehrsforschung; ifeu Institut für Energie- und Umweltforschung Heidelberg $\mathrm{GmbH}$; Ludwig-Bölkow-Systemtechnik GmbH (LBST); Deutsches Biomasseforschungszentrum $\mathrm{gGmbH}$ (DBFZ); München/Ottobrunn, Heidelberg, Leipzig, Berlin, 06.03.2014. http://biogasrat.de/wp-content/uploads/2018/01/mkskurzstudie-lng.pdf.

[17] Prenzler, Christian: Tesla Semi unveiled: 500+ range, Bugattibeating aero, 2019 production. https://www.teslarati.com/tesla-semi-unveiled-coming-2019500-mile-range/. Teslarati. Posted on 16.11.2017.

[18] Rosenberger, T.: Keine Kompromisse. trans aktuell 24. ETM Verlag, Stuttgart.1.12.2017.

[19] Lanzinger, R.: Eingebauter Umweltschutz. trans aktuell 12. ETM Verlag, Stuttgart. 8.6.2018. 